\title{
QTc interval prolongation, COVID-19 and chloroquine
}

\section{Wiwanitkit}

Accepted: 6 October 2020 / Published online: 8 October 2020 (C) The Author(s) 2020

Dear editor,

I would like to share my ideas on the article titled 'The risk of QTc-interval prolongation in COVID19 patients treated with chloroquine', which was recently published in the Netherlands Heart Journal [1]. Herein, Sinkeler et al. reported that 'Chloroquine treatment in COVID-19 patients gradually increased the QTc interval' [1]. Indeed, prolongation of the QTc interval is a possible cardiac electrophysiological change in anyone who receives chloroquine [2].

Although I agree with the authors that this requires monitoring, a point to be discussed is the chance that there is a clinically significant QTc interval prolongation. I would like to draw attention to the data from Indochina, where malaria is common and chloroquine is widely used. There are no reports on problems due to QTc interval prolongation among local people who use antimalarial prophylaxis, nor on cardiophysiological disturbances in COVID-19 patients receiving chloroquine therapy. Indeed, COVID19 might cause arrhythmia without chloroquine therapy [3]. Moreover, in the present report by Sinkeler et al. [1], there are no comparative data on QTc interval prolongation in COVID-19 patients who receive another treatment or data from other patients.

Conflict of interest V. Wiwanitkit declares that he has no competing interests.

Open Access This article is licensed under a Creative Commons Attribution 4.0 International License, which permits use, sharing, adaptation, distribution and reproduction in any medium or format, as long as you give appropriate credit to the original author(s) and the source, provide a link to the Creative Commons licence, and indicate if changes were made. The images or other third party material in this article are included in the article's Creative Commons licence, unless indicated otherwise in a credit line to the material. If material is not included in the article's Creative Commons licence and your intended use is not permitted by statutory regulation or exceeds the permitted use, you will need to obtain permission directly from the copyright holder. To view a copy of this licence, visit http://creativecommons.org/licenses/by/4.0/.

\section{References}

1. Sinkeler FS, Berger FA, Muntinga HJ, Jansen MMPM. The risk of QTc-interval prolongation in COVID-19 patients treated with chloroquine. Neth Heart J. 2020;28:418-23. https://doi.org/10.1007/s12471-020-01462-6.

2. Offerhaus JA, Wilde AAM, Prophylactic RCA. (hydroxy) chloroquine in COVID-19: potential relevance for cardiac arrhythmia risk. Heart Rhythm. 2020;17:1480-6.

3. Bandyopadhyay D, Akhtar T, Hajra A, Gupta M, Das A, Chakraborty S. et al. COVID-19 pandemic: cardiovascular complications and future implications. Am J Cardiovasc Drugs. 2020;20:311-24.
V. Wiwanitkit $(\bowtie)$
Dr. D.Y. Patil University, Pune, India

Hainan Medical University, Haikou, China

wviroj@yahoo.com 